\title{
Article \\ The Structure of Lenticular Crystals Formed in Plastically Deformed Titanium Nickelide
}

\author{
Fedor M. Noskov ${ }^{1, *}$, Ludmila I. Kveglis ${ }^{1}$, Artur K. Abkaryan ${ }^{1}$ and Rimma Y. Sakenova ${ }^{2}$ \\ 1 Department of Materials Science and Technology of Materials Processing, Polytechnic Institute, Siberian \\ Federal University, 660074 Krasnoyarsk, Russia; kveglis@list.ru (L.I.K.); abkaryan_artur@mail.ru (A.K.A.) \\ 2 Physics Department, Amanzholov East Kazakhstan University, Oskemen 070002, Kazakhstan; \\ Sakenova_rimma@mail.ru \\ * Correspondence: fnoskov@sfu-kras.ru
}

check for updates

Citation: Noskov, F.M.; Kveglis, L.I.; Abkaryan, A.K.; Sakenova, R.Y. The Structure of Lenticular Crystals Formed in Plastically Deformed Titanium Nickelide. Crystals 2022, 12, 145. https://doi.org/10.3390/ cryst12020145

Academic Editors: Yuanfei Han, Zhonggang Sun, Hong Li and Lechun Xie

Received: 20 December 2021

Accepted: 18 January 2022

Published: 20 January 2022

Publisher's Note: MDPI stays neutral with regard to jurisdictional claims in published maps and institutional affiliations.

Copyright: (C) 2022 by the authors. Licensee MDPI, Basel, Switzerland. This article is an open access article distributed under the terms and conditions of the Creative Commons Attribution (CC BY) license (https:// creativecommons.org/licenses/by/ $4.0 /)$.

\begin{abstract}
Samples of $\mathrm{Ni}_{51} \mathrm{Ti}_{49}$ alloy subjected to plastic deformation have been studied. The microstructure was studied by transmission electron microscopy and microdifraction on a Hitachi 7700 microscope. The phase composition of the samples was determined by X-ray diffraction in a Bruker diffractometer. Magnetometric measurements were performed in an induction petlescope. Lenticular crystals (of the $\mathrm{Ni}_{2} \mathrm{Ti}_{3}$ phase containing bend-extinction contours indicating a significant curvature of the crystal lattice appearing in the localization zones of plastic deformation) were found in the deformation localization zones. It was revealed that the samples are non-magnetic before deformation, but after plastic deformation, they have non-zero magnetization, which is associated with the emergence of new phases. Under conditions of local curvature of the crystal lattice, special structural states arise in zones of increased interatomic distances, which increase the number of degrees of freedom in the deformable solid and thus contribute to the redistribution of the components of the initial solid solution and the appearance of new phases. It was shown that the crystalline structure of lenticular crystals is a phase constructed of a spinel structural type with a crystal lattice parameter of $11.53 \pm 0.03 \AA$.
\end{abstract}

Keywords: titanium nickelide; plastic deformation; lenticular crystals; bend-extinction contours; magnetization; spinel

\section{Introduction}

Alloys based on titanium nickelide are increasingly widely used as functional materials in engineering and medicine due to the fact that they have a set of unique physical and mechanical properties. [1-6].

It is known [7-10] that the features of the martensitic transformation in the NiTi alloy, such as the transformation temperature, the presence and number of intermediate phases, whether the transformation is superplastic or not, strongly depend on the presence of $\mathrm{Ni}_{4} \mathrm{Ti}_{3}, \mathrm{Ti}_{2} \mathrm{Ni}$, etc. The secretions can be formed after heat treatment-quenching and annealing [2], or after deformation [11]. Studies of the morphology of these secretions have shown that the secretions have a lenticular shape $[12,13]$. The secretions can correspond to both equilibrium states $\left(\mathrm{TiNi}_{3}, \mathrm{Ti}_{2} \mathrm{Ni}_{3}, \mathrm{TiNi}, \mathrm{Ti}_{2} \mathrm{Ni}\right)$ [14] and nonequilibrium $\left(\mathrm{Ti}_{11} \mathrm{Ni}_{14}\right)$ [14], $\left(\mathrm{Ti}_{3} \mathrm{Ni}_{4}\right)$ [15], and the latter can reach a size of $700 \mathrm{~nm}$ [13]. $\mathrm{Ni}_{4} \mathrm{Ti}_{3}$ secretions are enriched with $\mathrm{Ni}$, the structure of these secretions was first described in [15] as rhombohedral with the space group R3. Studies of the morphology of these secretions have shown that the secretions have the shape of a lens with eight possible orientational variants, which was confirmed in [16,17].

In addition, the structure of titanium nickelide may contain the release of the equilibrium oxide phase $\mathrm{Ti}_{4} \mathrm{Ni}_{2} \mathrm{O}$ [13]. 
The main factor of phase formation during martensitic transformations in titanium nickelide is the correlation of events at different scale levels [18]. The processes of restructuring the crystalline medium can be described as a complex hierarchical process. Martensitic transformations are determined by elementary acts of cooperative movement of atoms and the formation of a specific self-organized martensitic macrostructure. During the formation of such a structure, the formation of secretions of various phases can occur.

Many researchers [19-22] have observed the appearance of lenticular single crystals as a result of exposure to an electron beam on amorphous films of metals and their compounds. These lenticular crystals contained a large number of bend-extinction contours. Such contours characterize the presence of a large curvature of the crystal lattice, which occurs due to the concentration of stresses in localized areas [23].

The formation of lenticular crystals, as already indicated, leads to a change in various properties, including magnetic ones. In [24], we have shown that as a result of multiple cycles of forward-reverse martensitic transition in titanium nickelide, mechanochemical processes can be carried out, leading to the delamination of the alloy and the release of ferromagnetic particles enriched with nickel.

In our work [25], from the position of modular self-organization, a scheme of martensitic transformations in titanium nickelide from the B2 structure (BCC lattice) to the B19 structure (GPU lattice) through an intermediate phase with an HCC lattice is proposed. In addition, the experimentally revealed occurrence of magnetization (in a usually nonmagnetic alloy) in a plastically deformed $\mathrm{Ni}_{51} \mathrm{Ti}_{49}$ alloy can be explained by the appearance of tetrahedrally densely packed $\mathrm{Ni}_{4} \mathrm{Ti}_{3}$ phase clusters in the curvature zones of the crystal lattice. In [25], the results of calculating the spin-polarized density of electronic states and magnetic moments of tetrahedrally densely packed $\mathrm{Ni}_{4} \mathrm{Ti}_{3}$ phase clusters are presented. The calculation is made for electrons with different spin projections: "up" and "down" carried out by the scattered wave method (for undeformed (with the same bond length), and for deformed cluster (the lengths of individual bonds are shortened)). The calculation showed a high density of states near the Fermi level, which is a characteristic feature of ferromagnetic metals.

Examples of obtaining a phase of the $\mathrm{Ni}_{2} \mathrm{Ti}_{3}$ type are known. Thus, in [26], such a phase was obtained by sintering with a high-power electric current of powder compresses made of pure nickel and titanium taken in equal proportions. In [27], several maximums in the X-ray diffraction pattern belonging to the $\mathrm{Ni}_{2} \mathrm{Ti}_{3}$ phase were identified. However, the structural type of this phase is not defined. This phase is also absent in the ASTM tables.

In [28], powders of pure titanium and nickel taken in a proportion corresponding to the compound $\mathrm{Ni}_{2} \mathrm{Ti}_{3}$ were fused by induction. After that, the alloy was mechanically ground into powder, which in turn was mechanically activated in a drum activator with balls in an argon atmosphere for 10 hours. The X-ray diffraction spectrum presented in [28] of the alloy after melting in an induction furnace demonstrated the presence of two phases $\mathrm{NiTi}+\mathrm{Ti}_{2} \mathrm{Ni}$. The $\mathrm{Ni}_{2} \mathrm{Ti}_{3}$ phase was not observed. The spectrum of the alloy after mechanical activation is characterized by a nanocrystalline state with a high degree of dispersion.

The authors of work [29] obtained an alloy of titanium nickelide from a powder mixture using its plastic deformation by explosion. As a result, the samples contained, in addition to the matrix with the structure B2 with martensites $\mathrm{R}$ and B19', a certain number of lenticular crystals $\mathrm{Ti}_{2} \mathrm{Ni}, \mathrm{Ti}_{3} \mathrm{Ni}_{4}, \mathrm{Ti}_{2} \mathrm{Ni}_{3}$ with internal inhomogeneities.

Thus, the study of the compound $\mathrm{Ni}_{2} \mathrm{Ti}_{3}$ is of scientific and practical interest.

Objective: To investigate the structure of lenticular crystals of $\mathrm{Ni}_{2} \mathrm{Ti}_{3}$ composition formed during plastic deformation of titanium nickelide samples.

Goals: use electron microscopy and X-ray phase analysis to investigate the structure of deformed thinned massive $\mathrm{Ni}_{51} \mathrm{Ti}_{49}$ samples; usemagnetometric methods to record the occurrence of a new phase as a result of plastic deformation of the $\mathrm{Ni}_{51} \mathrm{Ti}_{49}$ alloy; use the method of electron diffraction to establish the structure of lenticular crystals formed during deformation. 


\section{Methodology}

The initial bars of the $\mathrm{Ni}_{51} \mathrm{Ti}_{49}$ alloy were rolled in calibers at a temperature of $800{ }^{\circ} \mathrm{C}$. Samples for mechanical tensile tests in the form of double blades were cut using electric spark cutting. Annealing and quenching of samples placed in a sealed quartz tube filled with argon were carried out in a chamber electric furnace. The samples were placed in the furnace after its preheating. The samples were heated to an annealing temperature of $950{ }^{\circ} \mathrm{C} \pm 20^{\circ} \mathrm{C}$ with exposure for one hour and cooling to room temperature in the oven. Quenching of annealed samples from a temperature of $850^{\circ} \mathrm{C}$ with preliminary exposure in the furnace for an hour was carried out in water.

The samples after metallographic processing were subjected to static stretching until rupture. Stretching of the samples was carried out on an electromechanical universal testing machine.

Stretched samples were thinned in the concentrated deformation area using the FIB installation. To study the samples by transmission electron microscopy (TEM), disks with a diameter of $3 \mathrm{~mm}$ were cut from the rupture zone, which were mechanically thinned to a thickness of about 200 microns and then electrochemically etched until a hole appeared in the center of the disk. The final stage of sample preparation was ion etching at the PIPS (Gatan) installation.

Some samples thinned for transmission electron microscopy were subjected to cryomechanical treatment by cyclic cooling in liquid nitrogen. As a result of cryomechanical processing, the samples experienced significant micro-deformations. The microstructure was studied by transmission electron microscopy and microdifraction on a Hitachi $7700 \mathrm{mi}-$ croscope (Schaumburg, IL, USA). The phase composition of the samples was determined by X-ray diffraction in a Bruker diffractometer (Billerica, MA, USA) using copper radiation.

Magnetic characteristics were evaluated on an induction loopscope designed to measure hysteresis loops for samples with magnetization from 20 Gs (including from thin magnetic films).

\section{Experimental Results}

Figure 1a shows a diffraction pattern obtained from a section of the $\mathrm{Ni}_{51} \mathrm{Ti}_{49}$ sample subjected to a tensile load, which is a view of an atomically ordered structure of type B2, as evidenced by the presence of superstructural reflexes of type (001). Figure $1 \mathrm{~b}$ shows a dark-field image obtained in a transmission electron microscope, which demonstrates the nucleation of a lenticular crystal at the junction of three grains in the sample $\mathrm{Ni}_{51} \mathrm{Ti}_{49}$ (directed by the arrow). The image was obtained in the light of the selected reflex of the diffractogram shown in the insert. The origin of a lenticular crystal occurs at the junction of three grains, where the concentration of internal stresses is increased. The formation of similar lenticular crystals with bend-extinction contours in such an alloy was observed in [30].

Figure 2 shows an electron microscopic image of a refined $\mathrm{Ni}_{51} \mathrm{Ti}_{49}$ alloy sample subjected to cryomechanical treatment in liquid nitrogen and the corresponding electronogram. The white stripe coming from the lower right corner of Figure 2a represents the area of the crack tip at the end of which (in the center, at the top of Figure 2a) there is a region of localized deformation that has formed lenticular crystals with numerous bend-extinction contours. Contours in and out of lenticular crystals (1, 2, 3 in Figure 2a) are of different widths and are oriented in different directions, which indicate the heterogeneity of the stress distribution. The observed bend-extinction contours are optical effects of electron microscopy caused by strong local bending of atomic planes [19]. 


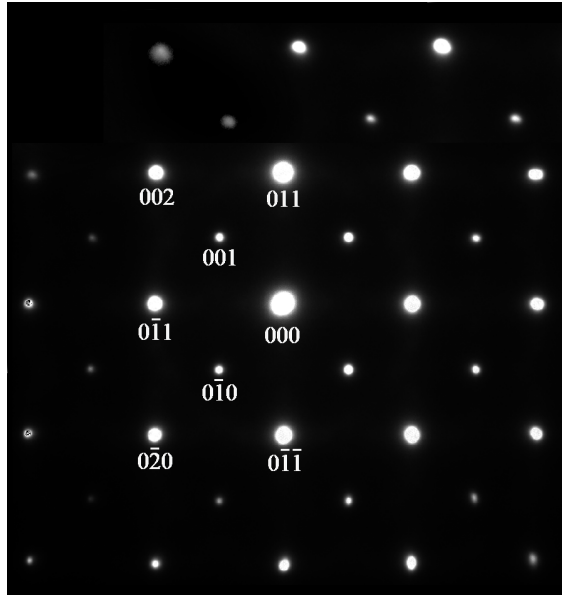

(a)

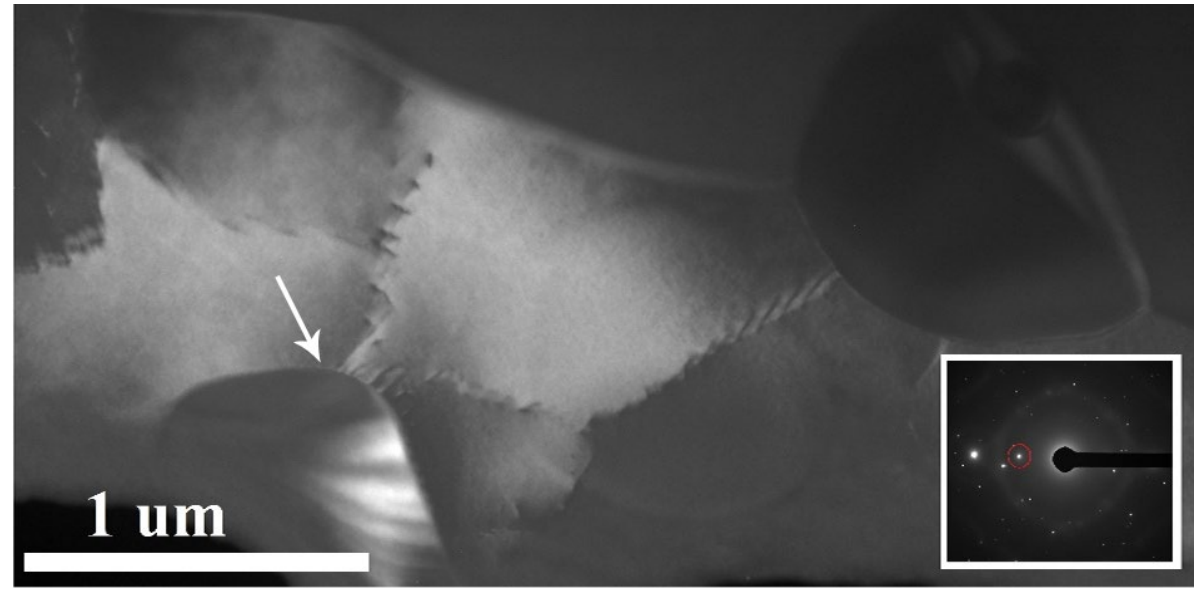

(b)

Figure 1. Diffraction pattern obtained from a section of the $\mathrm{Ni}_{51} \mathrm{Ti}_{49}$ sample subjected to a tensile load: (a) atomically ordered structure B2; (b) dark-field TEM image of the lenticular crystal nucleation region at the junction of three grains obtained in the light of the selected reflex on the insert.

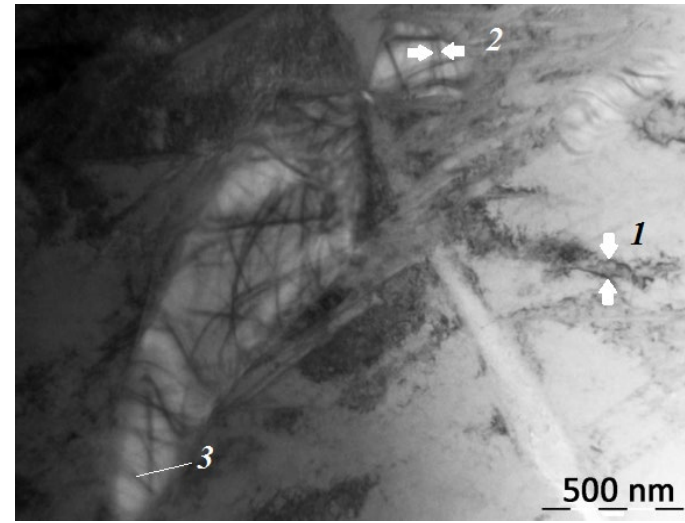

(a)

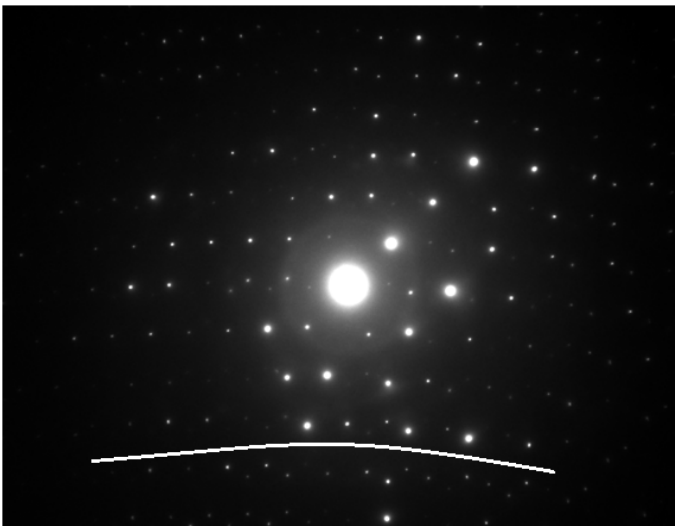

(b)

Figure 2. Investigation of the crack tip in a thinned $\mathrm{Ni}_{51} \mathrm{Ti}_{49}$ sample subjected to cryomechanical treatment in liquid nitrogen: (a) image obtained in a transmission electron microscope, (b) electronogram of this site.

The electronogram taken from the crack tip area (Figure $2 b$ ) contains bifurcated reflexes, the position of which is regularly shifted (underlined by a white line in Figure $2 b$ ), which indicates a strong bending of the crystal lattice.

Figure 3 shows an image obtained from a high-resolution transmission electron microscope from the zone of the flexural extinction contour. It is clearly visible that, in the left part of the image, there is a bend of the atomic planes underlined by a black line. The bend-contour technique reveals an unusual phenomenon of regular internal bending of the lattice planes associated with plastic deformation, which creates new crystalline forms [19]. Plastic deformation creates a bend in the crystal lattice (Figure 3), thereby causing a redistribution of the electron density and the emergence of new structural states [31]. In our case, this leads to the formation of lenticular crystals with a special structure (Figure 4). 


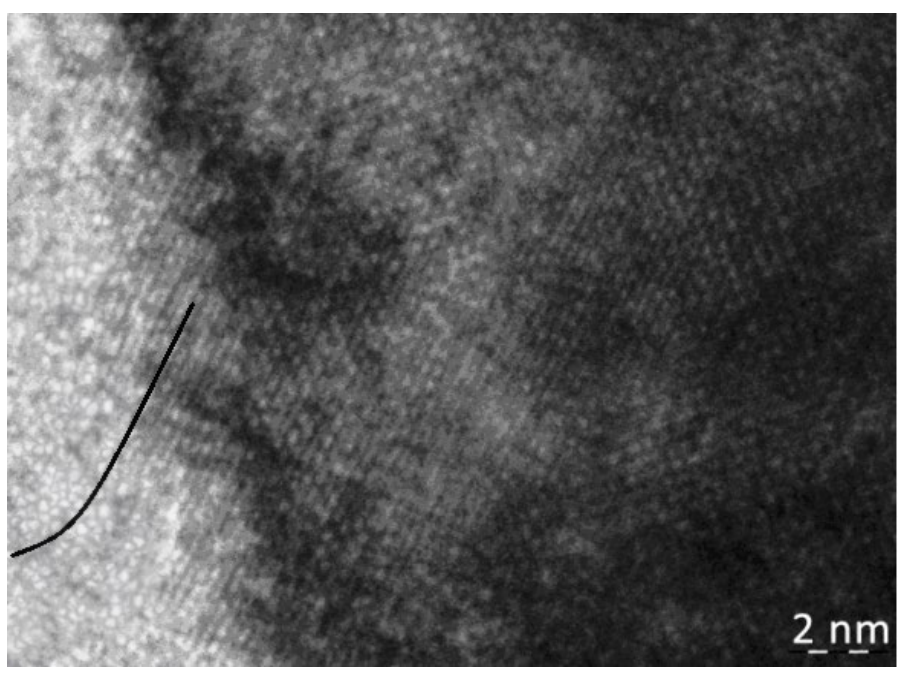

Figure 3. Image from the zone of the flexural extinction contour obtained in a high-resolution transmission electron microscope.

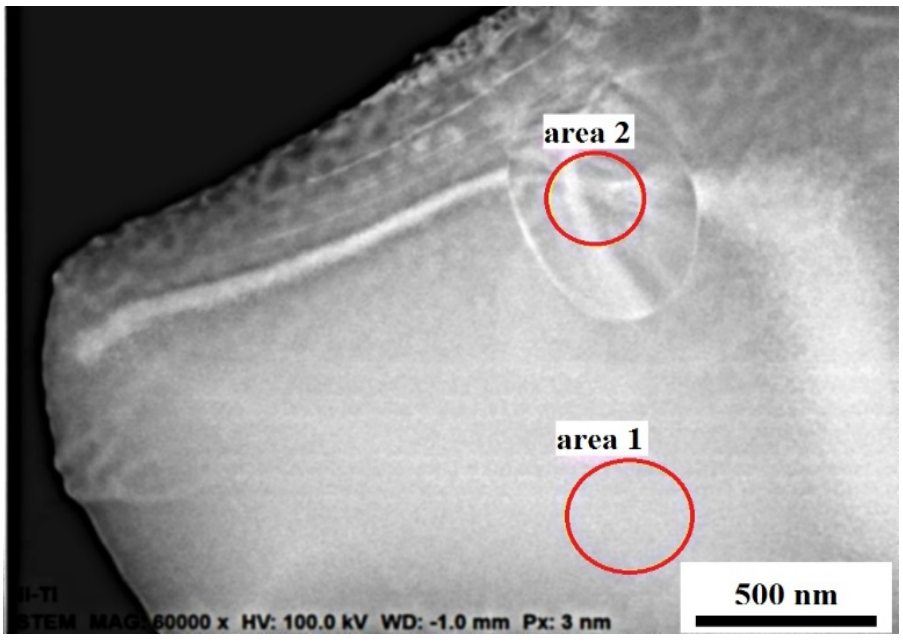

Figure 4. Image of a section of a deformed titanium nickelide sample obtained by scanning transmission electron microscopy.

Figure 4 shows an image of a refined $\mathrm{Ni}_{51} \mathrm{Ti}_{49}$ alloy sample subjected to a tensile load, obtained in a scanning transmission mode (dark-field image) on a transmission electron microscope. The pole of convergence of the bend-extinction contours is observed in the center of the lenticular crystal. The greatest concentration of internal stresses is concentrated in the pole zone. Spectral analysis data from two sites, from the pole zone (area 2) and away from it (area 1) (Figure 4), are summarized in Table 1.

Table 1. Chemical composition of the areas shown in Figure 3.

\begin{tabular}{ccc}
\hline at. $\%$ & Area 1 & Area 2 \\
\hline $\mathrm{Ni}$ & 51.3 & 41.7 \\
\hline $\mathrm{Ti}$ & 48.7 & 58.3 \\
\hline
\end{tabular}

In area 2, where the pole of the bend-extinction contour is located, there is a significant decrease in the amount of nickel and an increase in the amount of titanium compared to the initial composition (Table 1). The chemical composition of the lenticular crystal corresponds to the intermetallic $\mathrm{Ni}_{2} \mathrm{Ti}_{3}$. 
Analysis of the X-ray spectrum indicates the absence of oxygen spinel $\mathrm{Ni}_{2} \mathrm{Ti}_{4} \mathrm{O}$ in the structure of the studied samples.

Figure 5 shows the magnetic hysteresis loops of the $\mathrm{Ni}_{51} \mathrm{Ti}_{49}$ alloy sample obtained on an induction petlescope before (1) and after (2) plastic deformation. It can be seen that after plastic deformation, the sample has a nonzero magnetization, which is caused by the formation of $\mathrm{Ni}_{2} \mathrm{Ti}_{3}$ in its phase (Figure 5). In the zone of localization of plastic deformation, during the curvature of the crystal lattice interstitial bifurcation structural states arise [31], due to which an anomalous directional mass transfer is possible. It is obvious that the redistribution of components occurred as a result of plastic deformation since the sample did not have magnetization before deformation, and after deformation it becomes ferromagnetic.

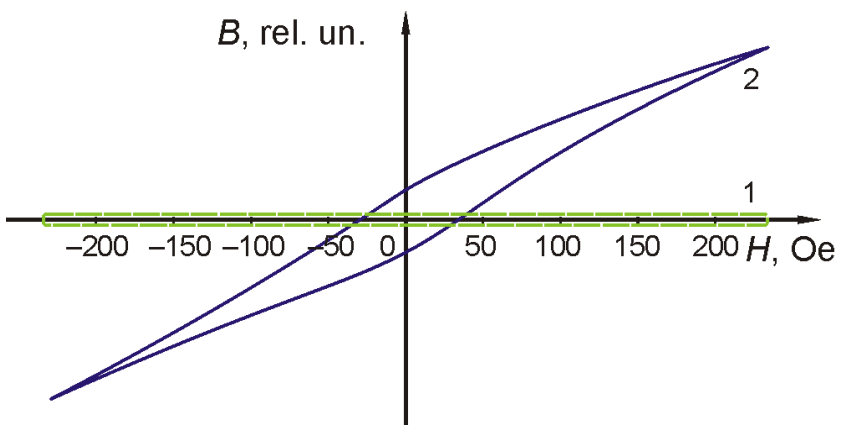

Figure 5. Hysteresis loops of $\mathrm{Ni}_{51} \mathrm{Ti}_{49}$ alloy before (1) and after (2) plastic deformation.

Figure 6a shows an electron microscopic image of the refined $\mathrm{Ni}_{51} \mathrm{Ti}_{49}$ sample in the concentrated deformation region of the sample stretched to rupture. A lenticular crystal with bend-contours inside is observed, indicating significant internal stresses arising in the crystal. The electron diffraction pattern obtained from this site is shown in Figure $6 \mathrm{~b}$. The same figure shows the scheme of decoding the resulting diffraction pattern is shown, the data is summarized in Table 2.

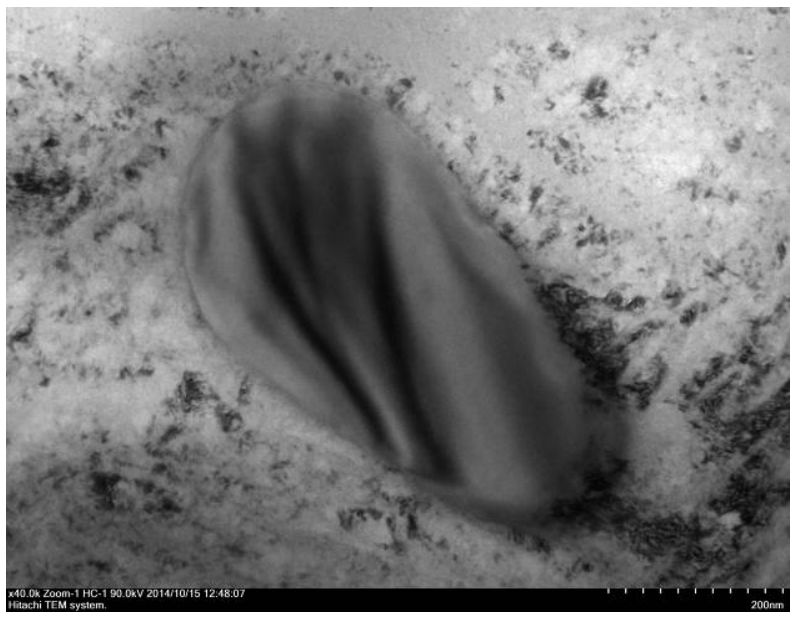

(a)

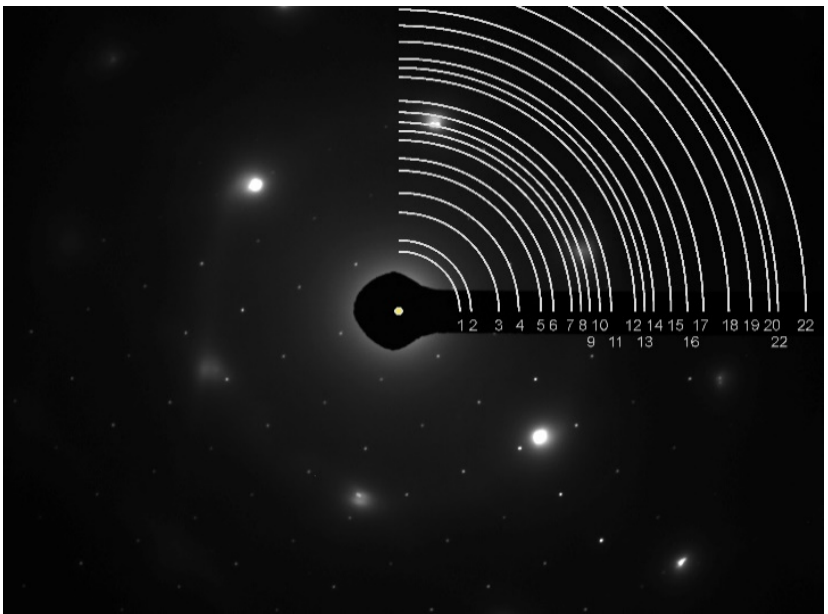

(b)

Figure 6. Electron microscopic image from the neck region of the stretched $\mathrm{Ni}_{51} \mathrm{Ti}_{49}$ sample (a) and electron diffraction from this region $(\mathbf{b})$. 
Table 2. The results of decoding the diffraction pattern shown in Figure 6.

\begin{tabular}{|c|c|c|c|}
\hline Line Number & $d, \AA$ & $\begin{array}{l}\text { Matrix B2, } \\
h k l(\Delta d, \AA)\end{array}$ & $\begin{array}{l}\text { Indexes of the Orientation [110] } \\
\text { Spinel Structure, } h k l(\Delta d, \AA)\end{array}$ \\
\hline 1. & 6,65 & & $111(0,00)$ \\
\hline 2. & 5,61 & & $200(+0,15) ; \frac{1}{2} 20(-0,03)$ \\
\hline 3. & 4,05 & & $220(+0,02)$ \\
\hline 4. & 3,38 & & $311(+0,11)$ \\
\hline 5. & 2,85 & & $400(+0,03)$ \\
\hline 6. & 2,62 & & $331(+0,02)$ \\
\hline 7. & 2,34 & & $422(+0,01)$ \\
\hline 8. & 2,22 & & $511(0,00)$ \\
\hline 9. & 2,12 & $110(0,00)$ & \\
\hline 10. & 2,01 & & $440(+0,02)$ \\
\hline 11. & 1,91 & & $442(+0,01)$ \\
\hline 12. & 1,71 & & $533(+0,05)$ \\
\hline 13. & 1,65 & & $444(+0,01)$ \\
\hline 14. & 1,59 & & $551(+0,02)$ \\
\hline 15. & 1,49 & & $553(+0,01)$ \\
\hline 16. & 1,40 & & $644(0,00)$ \\
\hline 17. & 1,33 & & $751(0,00)$ \\
\hline 18. & 1,23 & $211(0,00)$ & $911(+0,03)$ \\
\hline 19. & 1,15 & & $933(+0,01)$ \\
\hline 20. & 1,09 & & $1040(-0,02)$ \\
\hline 21. & 1,07 & $220(-0,01)$ & $1042(-0,02)$ \\
\hline 22. & 0,99 & & $1060(0,00)$ \\
\hline
\end{tabular}

From Figure $6 \mathrm{~b}$, it is clearly seen that in addition to the B2 phase, there is a phase with an FCC lattice orientation in the alloy structure [110]. The transcript showed (Table 2) that the lenticular crystal has a spinel-type crystal lattice with a parameter of $11.51 \AA$. The main reflexes of the spinel structure are marked in bold, and the numbers in parentheses show how much should be added/subtracted from our experimental data to the ideal calculated indicator.

Figure 7 shows an electron microscopic image of the refined $\mathrm{Ni}_{51} \mathrm{Ti}_{49}$ sample in the neck region of the sample stretched to rupture and a picture of electron diffraction from this area.

The results of the analysis of lenticular allocation from Figure 7 are generally similar to the previous case. It can be seen that in addition to the $\mathrm{B} 2$ phase, there is a phase in the alloy structure with an FCC lattice orientation [211]. From Table 3, it can be seen that the lenticular crystal has a spinel structure with a parameter of $11.55 \AA$. 


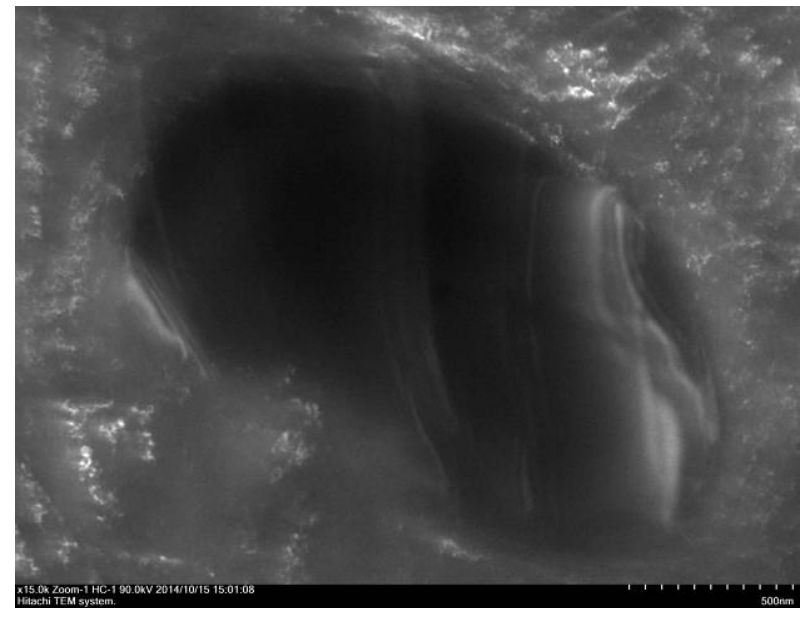

(a)

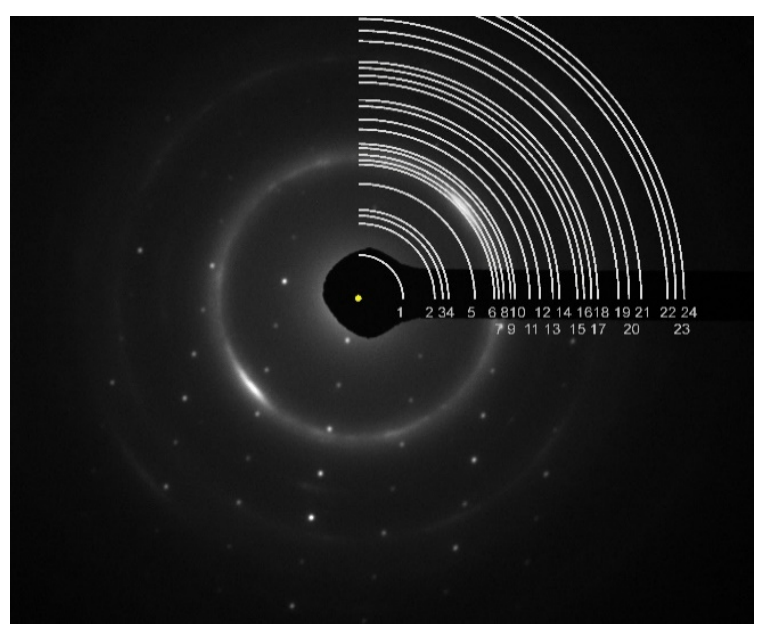

(b)

Figure 7. Electron microscopic image from the neck region of the stretched $\mathrm{Ni}_{51} \mathrm{Ti}_{49}$ sample in the dark field mode (a) and electron diffraction from this region (b).

Table 3. Results of decoding the diffraction pattern shown in Figure 7.

\begin{tabular}{|c|c|c|c|}
\hline Line Number & $d, \AA$ & $\begin{array}{l}\text { Matrix B2, } \\
h k l(\Delta d, \AA)\end{array}$ & $\begin{array}{l}\text { Indexes of the Orientation [110] } \\
\text { Spinel Structure, } h k l(\Delta d, \AA)\end{array}$ \\
\hline 1. & 6,67 & & $111(0,00)$ \\
\hline 2. & 3,91 & & $220(+0,17) ; 221(-0,06)$ \\
\hline 3. & 3,53 & & $311(-0,05)$ \\
\hline 4. & 3,31 & & $222(+0,02)$ \\
\hline 5. & 2,56 & & $331(+0,09)$ \\
\hline 6. & 2,19 & & $511(+0,03)$ \\
\hline 7. & 2,12 & $110(0,00)$ & \\
\hline 8. & 2,04 & & $440(0,00)$ \\
\hline 9. & 1,95 & & $531(0,00)$ \\
\hline 10. & 1,90 & & $442(-0,03)$ \\
\hline 11. & 1,74 & & $533(+0,02)$ \\
\hline 12. & 1,64 & & $444(+0,03)$ \\
\hline 13. & 1,53 & & $642(+0,01)$ \\
\hline 14. & 1,48 & $200(+0,03)$ & \\
\hline 15. & 1,36 & & $660(0,00)$ \\
\hline 16. & 1,32 & & $751(+0,01)$ \\
\hline 17. & 1,27 & & $911(0,00)$ \\
\hline 18. & 1,24 & $211(-0,01)$ & \\
\hline 19. & 1,14 & & $933(+0,02)$ \\
\hline 20. & 1,10 & & $1040(-0,03)$ \\
\hline 21. & 1,05 & $220(+0,01)$ & \\
\hline 22. & 0,96 & & $971(+0,06)$ \\
\hline 23. & 0,94 & & $1060(+0,05)$ \\
\hline 24. & 0,91 & & $1062(+0,07)$ \\
\hline
\end{tabular}




\section{Discussion of the Results}

In recent decades, more and more attention has been paid to the problem of the nonlinearity of the behavior of a solid body during plastic deformation. However, this problem cannot be solved within the immutable structure of a translationally invariant crystal [32]. It was shown in [33] that stresses form the curvature of the crystal lattice, which originate and propagate along the intergrain boundary. Along with the origin of curvature along the grain boundary, a specific island structure is formed in the zone of the triple junction. This island zone grows as the load increases, which is schematically illustrated in [33]. These results are in good agreement with the data presented in Figure 1. The authors [33] believe that the problem was previously considered without taking into account self-consistency between processes taking place at different structural and scale levels. Continuum mechanics is traditionally used at the macro level, dislocation theory and methods of molecular dynamics at the micro level, and quantum mechanics apparatus at the nanoscale. Such approaches are essentially single-level. In the multilevel approach developed in physical mesomechanics, deformation fracture is considered as a self-consistent process at nano-, micro-, meso- and macroscale levels.

In mesomechanics, the curvature of the crystal lattice plays a fundamental role. The curvature of the crystal lattice is the result of irreversible curvature of the atomic planes of the crystal lattice under the influence of an external load.

According to the theory [32], the origin of deformation defects (which may includelenticular crystals growing under plastic deformation) must fulfill three conditions:

- the presence of areas of local tensile normal stresses, creating increased molar volume, which may occur as local structural transformation (as illustrated as lenticular crystals in the area of the tip of the crack in Figure 2);

- the action of moment stresses in these zones, which create a local curvature and the occurrence of a highly excited nonequilibrium state of the material in the curvature zone (Figures $2 \mathrm{~b}$ and 3 );

- the appearance of a newly permitted structural state in the curvature zone (lenticular crystal in Figures 4, 6 and 7).

If these conditions are met, then it is possible to form a deformation defect, which in our case is a lenticular crystal, by transferring excited atoms in the local curvature zone from the main nodes of the crystal lattice to new resolved structural states, since this lowers the thermodynamic Gibbs potential in the defect region.

From the analysis of the results obtained during the decoding of electron diffraction patterns from lenticular crystals of the $\mathrm{Ni}_{2} \mathrm{Ti}_{3}$ composition (Table 1 ), it follows that in the structure of the studied alloys, in addition to the matrix solid solution with the B2 structure, there is a phase with a structural type of spinel. Spinels have a set of the most intense reflexes (shown in bold in Tables 2 and 3), which are usually used for identification in reference literature, for example in [34]. In our experiment, a greater number of reflexes corresponding to the Fd3m symmetry were revealed. The large parameter of the crystal lattice itself indicates that an elementary cell having an Fd3m type structure contains additional atoms inside itself or has an internal structure. The crystal lattice parameter of the specified phase is $11.53 \pm 0.03 \AA$.

The structural type of spinel for intermetallic compounds of nickel and titanium is known. The ASTM $\mathrm{Ti}_{2} \mathrm{Ni}$ phase table (ASTM Map no. 18-0898) [35] shows that the phase has a structural type Fd3m (spinel) and a crystal lattice parameter equal to $11.27 \AA$.

The X-ray diffraction spectrum demonstrates the presence of a large number of coexisting phases, each of which corresponds to a set of local reflexes. Among the deciphered phases, austenite, martensite, and intermetallic phases are observed. Among them, there is also a system of reflexes from the $\mathrm{Ni}_{2} \mathrm{Ti}_{3}$ phase corresponding to Tables 2 and 3 . Here, it should be emphasized that the X-ray spectrum is an integral characteristic of the studied sample, and the electron diffraction spectra were taken from specific local areas characterized by the presence of lenticular crystals (Figures 6 and 7). 
X-ray studies demonstrate the absence of a $\mathrm{Ti}_{4} \mathrm{Ni}_{2} \mathrm{O}$ oxygen spinel in any significant amounts in the structure of the studied sample, which, combined with the indications of energy dispersion spectra indicating the absence of oxygen in the studied lenticular crystals, make it possible to confidently exclude that these crystals represent the $\mathrm{Ti}_{4} \mathrm{Ni}_{2} \mathrm{O}$ phase. Additional evidence is the difference in the parameters of the crystal lattice, which for oxygen spinels in titanium nickelide, varies in the range of $11.27-11.35 \AA$, which is slightly less than the $11.53 \pm 0.03 \AA$ obtained in our experiment.

The analysis of Tables 2 and 3 shows that the displacement of diffraction reflexes from the calculated values practically does not exceed $0.15 \AA$. The displacement of the diffractogram lines in lenticular crystals experiencing curvature characterized by bendextinction contours (see Figures 6 and 7) is sufficiently well studied in the works of V.Y. Kolosov, for example in [19]. The curvature of the crystal lattices can partially explain the discrepancy between the interplane distances $d$ of the corresponding reflexes when comparing Tables 2 and 3. The possibility of displacement of atoms during martensitic transitions is experimentally shown in [36], where atoms can shift from their positions by up to $0.2 \AA$. In the works of Pushin V.G., for example [37], the possibility of significantly large atomic displacements in titanium nickelide is shown.

There are differences in the internal morphology of equilibrium and nonequilibrium phases when observed in an electron microscope. Thus, according to [38], the $\mathrm{Ti}_{4} \mathrm{Ni}_{2} \mathrm{O}$ phase is characterized by a homogeneous internal structure, and the $\mathrm{Ti}_{3} \mathrm{Ni}_{4}$ phase in the $\mathrm{Ni}_{50.8} \mathrm{Ti}_{49.2}$ alloy, for example, in [13], is characterized by the presence of clearly distinguishable bend-contours, indicating significant internal stresses.

The appearance of bend-extinction contours can be explained on the basis of calculations of local stresses in the pre-fracture zone made in [39]. However, if [39] describes the occurrence of a lenticular crack in the pre-fracture zone, then our work shows that lenticular crystals with bend-contours inside appear in the pre-fracture zone (at the tip of the crack). Thus, the localization of deformation in our case leads to the emergence of an "intermediate" state between the state of pre-destruction and destruction-the formation of a nonequilibrium phase with the morphology of a lenticular crystal with significant internal stresses.

It is obvious that for the formation of lenticular crystals of the nonequilibrium $\mathrm{Ni}_{2} \mathrm{Ti}_{3}$ phase, it is necessary to redistribute the components of the initial solid solution or intermetallic phases. Under conditions of local curvature of the crystal lattice, special structural states arise in zones of increased interatomic distances, which increase the number of degrees of freedom in a deformable solid. In [31], such states were called interstitial bifurcation structural states (IBSS). Due to the occurrence of IBSS in a deformed metal, it is possible to realize directional mass transfer occurring at the rate of switching of interatomic bonds, which in some cases can reach the speed of sound in the metal [40].

The experimentally revealed occurrence of magnetization in the plastically deformed $\mathrm{Ni}_{51} \mathrm{Ti}_{49}$ alloy can be explained by the appearance of tetrahedrically densely packed $\mathrm{Ni}_{2} \mathrm{Ti}_{3}$ phase clusters with a spinel structure in the zones of curvature of the crystal lattice [25].

\section{Conclusions}

1. In titanium nickelide samples subjected to plastic deformation, lenticular crystals of the $\mathrm{Ni}_{2} \mathrm{Ti}_{3}$ phase containing bend-extinction contours were found, indicating significant internal stresses in localized areas.

2. The crystal structure of lenticular crystals $\mathrm{Ni}_{2} \mathrm{Ti}_{3}$ is in a phase having a spinel structural type with a crystal lattice parameter of $11.53 \pm 0.03 \AA$.

3. The studied $\mathrm{Ni}_{51} \mathrm{Ti}_{49}$ alloy samples that have undergone plastic deformation have a significant magnetization caused by the growth of a new ferromagnetic phase $\mathrm{Ni}_{2} \mathrm{Ti}_{3}$. 


\begin{abstract}
Author Contributions: Conceptualization, F.M.N. and L.I.K.; methodology, L.I.K. and A.K.A.; software, F.M.N. and R.Y.S.; validation, L.I.K. and F.M.N.; formal analysis, L.I.K.; investigation, L.I.K. and A.K.A.; resources, R.Y.S.; data curation, F.M.N.; writing-original draft preparation, A.K.A.; writing-review and editing, F.M.N. and L.I.K.; visualization, F.M.N.; supervision, L.I.K.; project administration, F.M.N.; funding acquisition, F.M.N. and L.I.K. All authors have read and agreed to the published version of the manuscript.
\end{abstract}

Funding: This research received no external funding.

Institutional Review Board Statement: Not applicable.

Informed Consent Statement: Not applicable.

Data Availability Statement: Not applicable.

Acknowledgments: The authors express their gratitude to M. N. Volochaev (Kirensky Institute of Physics, Krasnoyarsk, Russia) for his help in conducting the experiment.

Conflicts of Interest: The authors declare no conflict of interest.

\title{
References
}

1. Likhachev, V.A.; Kuzmin, S.L.; Kamentsova, Z.P. The Shape Memory Effect; LSU: Leningrad, Russia, 1987 ; p. 216.

2. Gunter, V.E.; Khodorenko, V.N.; Yasenchuk, Y.F. Titanium Nickelide. New Generation Medical Material; MIT: Tomsk, Russia, 2006; p. 296.

3. Malygin, G.A. Diffuse martensitic transitions and the plasticity of crystals with a shape memory effect. Phys.-Uspekhi 2001, 44 , 173. [CrossRef]

4. $\quad$ Potekaev, A.I.; Klopotov, A.A.; Kozlov, E.V.; Kulagina, V.V. Weakly Stable Pre-Transition Structures in Titanium Nickelide; Publishing House of NTL: Tomsk, Russia, 2004; p. 296.

5. Otsuka, K.; Ren, X. Physical metallurgy of Ti-Ni-based shape memory alloys. Prog. Mater. Sci. 2005, 50, 511-678. [CrossRef]

6. Otsuka, K.; Suzuki, Y.; Shimizu, K. Alloys with Shape Memory Effect; Metallurgiya: Moscow, Russia, 1990; p. 224.

7. Zel'Dovich, V.; Sobyanina, G.; Novoselova, T.V. Martensitic transformations in TiNi alloys with Ti3Ni4 precipitates. J. Phys. 1997, 7, 299-304. [CrossRef]

8. Bataillard, L.; Bidaux, J.-E.; Gotthardt, R. Interaction between microstructure and multiple-step transformation in binary NiTi alloys using in-situ transmission electron microscopy observations. Philos. Mag. A 1998, 78, 327-344. [CrossRef]

9. Khalil-Allafi, J.; Dlouhy, A.; Eggeler, G. Ni4Ti3-precipitation during aging of NiTi shape memory alloys and its influence on martensitic phase transformations. Acta Mater. 2002, 50, 4255-4274. [CrossRef]

10. Filip, P.; Mazanec, K. On precipitation kinetics in TiNi shape memoryalloys. Scr. Mater. 2001, 45, 701-707. [CrossRef]

11. Tirry, W.; Schryvers, D.; Jorissen, K.; Lamoen, D. Electron-diffraction structure refinement of Ni4Ti3 precipitates in Ni52Ti48. Acta Crystallogr. 2006, 62, 966-971. [CrossRef]

12. Li, Z.Q.; Sun, Q.P. The initiation and growth of macroscopic martensite band in nano-grained NiTi microtube under tension. Int. J. Plast. 2002, 18, 1481-1498. [CrossRef]

13. Efstathiou, C.; Sehitoglu, H. Local transformation strain measurements in precipitated NiTi single crystals. Scr. Mater. 2008, 59, 1263-1266. [CrossRef]

14. Klopotov, A.A.; Gunter, V.E.; Marchenko, E.S.; Yasenchuk, Y.F.; Klopotov, V.D.; Kozlov, E.V. Crystallogeometry of structures in Ti-Ni, Ti-Fe and Ti-Ni-Fe systems. Fundam. Probl. Mod. Mater. Sci. 2009, 6, 81-90.

15. Tadaki, T.; Nakata, Y.; Shimizu, K.; Otsuka, K. Crystal Structure, Composition and Morphology of a Precipitate in an aged Ti-51 at\%Ni Shape Memory Alloy. Trans. Jpn. Inst. Met. 1986, 27, 731-740. [CrossRef]

16. Nishida, M.; Wayman, C.M.; Honma, T. Precipitation processes in near-equiatomic TiNi shape memory alloys. Met. Trans. 1986, 17, 1505-1515. [CrossRef]

17. Nishida, M.; Wayman, C.M. Electron microscopy studies of precipitation processes in near-aquiatomic TiNi shape memory alloys. Mater. Sci. Eng. 1987, 93, 191-203. [CrossRef]

18. Plotnikov, V.A. Acoustic Energy Dissipation During Thermoelastic Martensitic Transformations in Titanium Nickelide-Based Alloys: Monograph; Publishing House AGU: Barnaul, Russia, 2013; p. 204.

19. Kolosov, V.Y.; Thölén, A.R. Transmission electron microscopy studies of the specific structure of crystals formed by phase transition in iron oxide amorphous films. Acta Mater. 2000, 48, 1829-1840. [CrossRef]

20. Bagmut, A.G. Electron Microscopy of Films Deposited by Laser Evaporation; Publishing House NTU "KhPI": Kharkiv, Russia, 2014; p. 304.

21. Kveglis, L.I. Structure Formation in Amorphous and Nanocrystalline Films of Alloys Based on Transition Metals: Dissertation. Ph.D. Thesis, Kirensky Institute of Physics, Krasnoyarsk, Russia, 2005; p. 280.

22. Bolotov, I.E.; Kolosov, V.Y. Electron microscope investigation of crystals based on bend-contour arrangement. I. Relationship between bend contour arrangement and bend geometry. Phys. Status Solidi A 1982, 69, 85-96. [CrossRef] 
23. Korotaev, A.D.; Tyumentsev, A.N.; Sukhovarov, V.F. Dispersion Hardening of Refractory Metals; Nauka: Novosibirsk, Russia, 1989; p. 210.

24. Abylkalykova, R.B.; Tazhibaeva, G.B.; Noskov, F.M.; Kveglis, L.I. The features of the martensitic transformation in titanium nickelide. Bull. Russ. Acad. Sci. Phys. 2009, 73, 1542-1544. [CrossRef]

25. Kveglis, L.I.; Noskov, F.M.; Volochaev, M.N.; Nyavro, A.V.; Filarowski, A. Magnetic Properties of Nickel-Titanium Alloy during Martensitic Transformations under Plastic and Elastic Deformation. Symmetry 2021, 13, 665. [CrossRef]

26. Yener, T.; Siddique, S.; Walther, F.; Zeytin, S. Effect of electric current on the production of NiTi intermetallics via electric-currentactivated sintering. MTAEC9 Mater. Technol. 2015, 49, 721-724. [CrossRef]

27. Ergin, N.; Ozdemir, O. An Investigation on TiNi Intermetallic Produced by Electric Current Activated Sintering. Acta Phys. Pol. A 2013, 123, 248-249. [CrossRef]

28. Xinxin, C.; Liqun, M.; Meng, Y.; Xiangyu, Z.; Yi, D. Electrochemical Properties of the Amorphous Ti3Ni2 Alloy in Ni/MH Batteries. Rare Met. Mater. Eng. 2012, 41, 1511-1515. [CrossRef]

29. Han, X.; Zou, W.; Wang, R.; Jin, S.; Zhang, Z.; Li, T.; Yang, D. Microstructure of TiNi shape-memory alloy synthesized by explosive shock-wave compression of Ti-Ni powder mixture. J. Mater. Sci. 1997, 32, 4723-4729. [CrossRef]

30. Bahador, A.; Hamzah, E.; Kondoh, K.; Abubakar, T.A.; Yusof, F.; Umeda, J.; Saud, S.; Ibrahim, M.K. Microstructure and superelastic properties of free forged Ti-Ni shape-memory alloy. Trans. Nonferrous Met. Soc. China 2018, 28, 502-514. [CrossRef]

31. Panin, V.E.; Egorushkin, V.E. Fundamentals of physical mesomechanics of plastic deformation and destruction of solids as nonlinear hierarchically organized systems. Phys. Mesomech. 2015, 18, 100-113. [CrossRef]

32. Panin, V.E.; Egorushkin, V.E.; Derevyagina, L.S.; Deryugin, E.E. Nonlinear wave processes of crack propagation in brittle and brittle-ductile fracture. Phys. Mesomech. 2013, 16, 183-190. [CrossRef]

33. Moiseenko, D.D.; Pochivalov, Y.I.; Maksimov, P.V.; Panin, V.E. Rotational deformation modes in near-boundary regions of grain structure in a loaded polycrystal. Phys. Mesomech. 2013, 16, 248-258. [CrossRef]

34. Gorelik, S.S.; Skakov, Y.A.; Rastorguev, L.N. X-ray and Electron-Optical Analysis; MISIS: Moscow, Russia, $1994 ;$ p. 328.

35. Yurko, G.A.; Barton, J.W.; Parr, J.G. The crystal structure of Ti2Ni. Acta Crystallogr. 1959, 12, 909-911. [CrossRef]

36. Lipson, H.; Parker, A.M.B. Structure of Martensite. J. Iron Steel Inst. 1944, 149, 123-141.

37. Pushin, V.G.; Kondratiev, V.V.; Khachin, V.N. Pre-Transition Phenomena and Martensitic Transformations; Ural Branch of the Russian Academy of Sciences: Yekaterinburg, Russia, 1998; p. 367.

38. Surikova, N.S. Regularities and Mechanisms of Plastic Deformation and Structural-Phase Transformations in Single Crystals of TiNi(Fe, Mo) and TiNi(Fe) Alloys: Dissertation. Ph.D. Thesis, Tomsk State University, Tomsk, Russia, 2011; p. 343.

39. Kornev, V.M. On diagrams of destruction of bodies with short macro cracks. Embrittlement of the material during fatigue failure. Phys. Mesomech. 2016, 19, 80-99.

40. Abylkalykova, R.B.; Kveglis, L.I.; Kalitova, A.A.; Noskov, F.M. Abnormally Fast Migration of Substance at Shock Loadings. Adv. Mater. Res. 2013, 871, 231-234. [CrossRef] 